\title{
HISTÓRIA DA ESCOLA DE APLICAÇ̃̃O DA FEUSP (1976-1986): A CONTRIBUIÇÃO DE JOSÉ MÁRIO PIRES AZANHA PARA A CULTURA ESCOLAR
}

Nívia Gordo

Universidade de São Paulo, Brasil

E-mail: niviagordo@uol.com.br

\author{
Carlota Boto \\ Universidade de São Paulo, Brasil \\ reisboto@usp.br
}

\begin{abstract}
RESUMO
No período de 1976 a 1986 a Escola de Aplicação (EA), vinculada à FEUSP, foi orientada por José Mário Pires Azanha com o objetivo de torná-la uma escola comum, à semelhança da escola pública. Dada a relevância da atuação de Azanha no que se referiu à reorganização e ao funcionamento da EA nos diversos aspectos de natureza técnico-administrativa e pedagógica e aos bons resultados alcançados na aprendizagem, são propostos como objetivos deste relato: descrever a história da EA no referido período; o posicionamento de Azanha frente ao movimento de renovação pedagógica nas décadas de 70 e 80; e identificar aspectos da teoria e da prática desenvolvidos na EA que possam ser viáveis na escola pública deste estado.
\end{abstract}

Palavras-chave: Escola de Aplicação. José Mário Pires Azanha. Renovação pedagógica.

HISTORIA DE LA ESCUELA DE APLICACIÓN DE LA FEUSP (1976-1986). LA CONTRIBUCIÓN DE JOSÉ MÁRIO PIRES AZANHA A LA CULTURA ESCOLAR

\section{RESUMEN}

De 1976 a 1986, la Escuela de Aplicación (EA), vinculada a la FEUSP, fue dirigida por José Mário Pires Azanha con el objetivo de convertirla en una escuela común, similar a la escuela pública. Dada la relevancia del desempeño de Azanha en cuanto a la reorganización y funcionamiento de la EA en los diversos aspectos de carácter técnico-administrativo y pedagógico y los buenos resultados logrados en el aprendizaje, se proponen los objetivos de este informe: describir: la historia de la EA en dicho período; La posición de Azanha frente al movimiento de renovación pedagógica de los años 70 y 80; e identificar aspectos de la teoría y la práctica desarrollados en EE que puedan ser viables en las escuelas públicas de este estado.

Palabras clave: Escuela de Aplicación. José Mário Pires Azanha. Renovación pedagógica.

\section{HISTORY OF THE SCHOOL OF APPLICATION AT FEUSP (1976-1986): JOSÉ MÁRIO PIRES AZANHA'S CONTRIBUTION TO SCHOOL CULTURE}

\begin{abstract}
From 1976 to 1986, the School of Application (EA), linked to FEUSP, was guided by José Mário Pires Azanha with the aim of turning it into a common school, similar to the public school. Given the relevance of Azanha's performance with regard to the reorganization and
\end{abstract}




\section{$(\mathrm{cc}) \mathrm{BY}$}

functioning of $\mathrm{EE}$ in the various aspects of a technical-administrative and pedagogical nature and the good results achieved in learning, the objectives of this report are proposed: to describe: the history of EE in said period; Azanha's position in the face of the pedagogical renewal movement in the 70s and 80s; and identify aspects of theory and practice developed in EE that may be viable in public schools in this state.

Keywords: School of Application. José Mário Pires Azanha. Pedagogical renewal.

\section{HISTOIRE DE L'ECOLE D'APPLICATION DE LA FEUSP (1976-1986): CONTRIBUTION DE JOSÉ MÁRIO PIRES AZANHA À LA CULTURE SCOLAIRE}

\section{RÉSUMÉ}

De 1976 à 1986, l'École d'application (EA), liée à la FEUSP, a été dirigée par José Mário Pires Azanha dans le but d'en faire une école commune, similaire à l'école publique. Compte tenu de la pertinence des performances d'Azanha en ce qui concerne la réorganisation et le fonctionnement de l'EE dans les différents aspects d'ordre technico-administratif et pédagogique et les bons résultats obtenus en apprentissage, les objectifs de ce rapport sont proposés : décrire: l'histoire de l'EE dans ladite période; la position d'Azanha face au mouvement de renouveau pédagogique des années 70 et 80; et identifier les aspects de la théorie et de la pratique développées en EE qui peuvent être viables dans les écoles publiques de cet État.

Mots-clés: École d'application. José Mario Pires Azanha. Renouveau pédagogique.

\section{INTRODUÇÃO}

A partir de 1972, a Faculdade de Educação assumiu a Escola de Demonstração dandolhe, por sugestão de Azanha, a denominação de Escola de Aplicação a fim de afirmar o caráter de uma escola comum. Assim, no período de 1976 a 1986, sob a orientação de Azanha, foram feitas outras mudanças na área técnico-administrativa e pedagógica; no corpo discente e docente, conforme são descritas, a seguir.

\section{REGIMENTO E OBJETIVO: ALTERAÇÕES FEITAS}

Azanha afirmou o caráter comum da EA mediante os seguintes objetivos: proporcionar escolaridade em nível de $1^{\circ}$ grau, aplicar e avaliar métodos educacionais previstos no Plano Escolar Anual; servir de campo de estudo a professores da Feusp e de estágio a seus alunos nas condições previstas no Plano Escolar Anual EA. Quanto às finalidades do ensino, Azanha apregoava "o desenvolvimento integral da personalidade humana e a sua participação na obra do bem comum" (AZANHA, 1987, p. 83). Azanha, que já participava da reforma do ensino na rede estadual, tomou esse dispositivo como referência para uma revisão da concepção do ensino 
primário: Outra crítica foi feita por ele à lei 4.024/1961 (artigo $1^{\circ}$ ) que propõe como uma das finalidades do ensino o desenvolvimento integral do ensino:

(...) pretender, por exemplo, que num contexto urbano-industrial em elevado estágio de desenvolvimento, a escola primária forme a personalidade integral do educando, não é, de maneira alguma, valorizar-lhe as funções. É antes uma colocação ingênua e até certo ponto prejudicial porque, desconsiderando as reais possibilidades de ação da escola primária, lhe propõe objetivos que, por inatingíveis, não propiciam ao processo educativo a orientação necessária à sua organização e desenvolvimento. Além disso, Azanha (1987, p. 83) deixa clara sua concepção de ensino que visa à formação de crianças nas séries iniciais

Uma instituição que retém a criança durante apenas algumas horas do dia quase sempre empobrecendo o seu ambiente, não pode, nem deve se propor à formação que permitam à criança, sob a orientação do professor_ uma integração de todas as suas experiências integral da personalidade dessa criança porque essa é uma tarefa irrealizável nessas condições. Mas pode e deve procurar exercer uma influência integradora das experiências que a criança viva, dentro e fora da escola, com vistas a desenvolvimento (sic) harmônico da personalidade do educando. Não é possível formar integralmente a criança no espaço de vida que ela passa na escola, mas esse período pode ser o ponto de partida para o desenvolvimento de hábitos e atitudes. (AZANHA, (1987, p.83)

\section{CURRÍCULO E PROGRAMAS DE ENSINO: 1976-1977}

$\mathrm{Na}$ proposta curricular para o ensino de $1^{\circ}$ grau, Azanha atendeu aos dispositivos da lei 5.692/1971 e às demais determinações emanadas dos órgãos responsáveis pela regulamentação do ensino, mas enfatizou, sobretudo, as disciplinas: língua portuguesa, inglesa e francesa; matemática; artes (artes plásticas e industriais e arte musical); história e geografia, atribuindolhes a maior carga horária possível. Essa seleção remonta à importância atribuída a um ensino de formação geral de caráter humanista que não enfatiza, portanto, os dispositivos de “sondagem de aptidões" ou de especialização para o trabalho.

A área de comunicação e expressão compreendeu as linguagens (verbal e não verbal), a saber: português, inglês e francês, ressaltando-se a língua portuguesa como o meio por excelência da comunicação e da integração nacional. Também foi reconhecida a importância, como meio de expressão e comunicação, das artes: física, plásticas, industriais, dramáticas, literárias entre outras, além da educação. Da mesma forma, também como consequência do currículo adotado, ocorreu notável mudança na área dos recursos didáticos, principalmente nos livros da literatura infanto-juvenil: contos de bons autores, revistas, jornais do folclore brasileiro. As aulas de francês e de inglês foram enriquecidas por meio de clubes que 


\section{$(\mathrm{Cc}) \mathrm{EY}$}

funcionavam em horário extra e contribuíram muito para a ampliação da cultura geral dos alunos. Quanto à matéria de Estudos Sociais, nas $5^{\mathrm{a}}$ e $6^{\mathrm{a}}$ séries, foram instituídas aulas de geografia e história, como já ocorria nas $7^{\mathrm{a}}$ e $8^{\mathrm{a}}$ séries.

Nas $3^{\mathrm{a}}, 4^{\mathrm{a}}, 5^{\mathrm{a}}$ e $6^{\mathrm{a}}$ séries a história e a geografia passaram a ser tratadas como área de estudo com a denominação de "Estudos Sociais" e nas $7^{\mathrm{a}}$ e $8^{\mathrm{a}}$ séries história e geografia foram tratadas como disciplinas de organização social e política - cuja destinação foi a do preparo para o exercício da cidadania. A disciplina educação moral e cívica foi estabelecida para as classes de $1^{\mathrm{a}}$ a $4^{\mathrm{a}}$ séries.

Matemática e ciências físicas e biológicas visaram ao desenvolvimento de iniciativas, pesquisa e à criatividade no nível de invenções e de compreensão do meio próximo e remoto. As artes plásticas e industriais foram tratadas como área de estudo nas classes de $5^{\mathrm{a}}$ à $8^{\mathrm{a}}$ série com o objetivo de formação especial voltada para a sondagem de aptidões e iniciação para o trabalho.

O currículo assim proposto decorreu da concepção de Azanha de que “... num espaço de apenas quatro horas diárias torna-se impraticável levar a bom termo um processo educativo de boa qualidade com um currículo sobrecarregado de disciplinas.” (1987, p. 84).

A verificação do rendimento escolar tinha os seguintes objetivos:

I. diagnosticar dificuldades de aprendizagem, tendo em vista a recuperação do aluno e o replanejamento dos trabalhos;

II. possibilitar ao aluno uma auto-avaliação (sic) sobre seu rendimento escolar de modo a interessá-lo em seu próprio progresso e aperfeiçoamento;

III. obter informações para decidir sobre a promoção do aluno e a reorganização das classes.

Foram propostas aulas de recuperação durante todo o ano letivo para alunos dificilmente recuperáveis na própria sala de aula. Considerando, ainda, a possibilidade da ocorrência de alunos com difícil aprendizagem, foi previsto para eles recuperação no início do ano letivo.

\section{ORGANIZAÇÃO DO PESSOAL TÉCNICO-ADMINISTRATIVO}

Em 1976, como a Escola de Aplicação estava sem diretor, Azanha convidou para o cargo a professora Ondina Gertrudes Annechino de Campos que se distinguiu como notável gestora. Além disso, foram incluídos no quadro de pessoal auxiliares de direção em substituição ao assistente de direção. Os auxiliares exerciam as seguintes atividades: substituir a própria diretora em sua ausência e, também, professores em suas faltas eventuais, inspeção de alunos, 


\section{$(\mathrm{Cc}) \mathrm{EY}$}

assistência a professores em suas atividades de rotina, atendimento aos pais, fornecimento de material didático, controle da limpeza das salas de aula e do horário de entrada e saída das classes.

Outra alteração consistiu na centralização da orientação técnica de todas as atividades com vistas à racionalização de esforço. As atividades antes atribuídas à Coordenação Pedagógica passaram a constituir atribuições de um único órgão - a coordenação técnica - que compreendia: professores orientadores das áreas de ensino, o orientador educacional e um responsável pela coordenação técnica. Assim, foram excluídas do Serviço de Assistência ao Aluno as funções relativas à assistência psicológica, fonoaudiologia, foniatria e educação sanitária. O objetivo foi o de tornar a EA semelhante a uma escola pública e também solucionar a falta de verbas. Foram mantidas as duas bibliotecárias devido à importância do seu trabalho de aquisição, manutenção e empréstimo de livros, principalmente da literatura infanto-juvenil e de textos informativos, aos alunos e professores. Conforme dispunha a lei 5.692/1971, foi designado um dos professores da área de estudos sociais para assumir a orientação do Centro Cívico Escolar com a finalidade de programar e realizar solenidades cívicas, promover atividades de cunho cívico e cultural; estimular a organização e funcionamento de classe e extraclasse do Estatuto Cívico Escolar.

Quanto à Associação Escola-Lar, contava-se com ampla participação dos pais tanto na organização das atividades sociais quanto nos serviços de consertos de equipamentos das dependências da escola, administração da cooperativa da escola, controle e planejamento das festas juninas. A coordenação técnica era constituída por professores orientadores, um para cada disciplina. Também cabia a essa coordenação acompanhar o trabalho docente e discutir e decidir eventuais problemas surgidos no decorrer das aulas.

De acordo com o Regimento Escolar a seleção do corpo docente era de responsabilidade de uma comissão composta pelo diretor da escola, do responsável pela coordenação técnica e o professor orientador da área afim.

Constituíam atribuições dos professores: participar da elaboração do Plano Escolar Anual e participar de todas as atividades extraclasse, comparecer às reuniões previstas no Plano Escolar Anual, programar atividades para o caso de suas eventuais faltas. Cada classe era composta por 30 alunos, matriculados após serem selecionados por sorteio público conforme foi estabelecido no Regimento Escolar. Desta forma, foi possível contar com uma clientela variada e evitar o excesso de alunos, uma vez que era grande a procura por matrículas. 


\section{ESTÁGIO}

A Escola de Aplicação tinha como objetivo oferecer estágio a alunos da Faculdade de Educação de acordo previamente estabelecido com os professores de Práticas. Foram atendidos estagiários do curso de pedagogia (Metodologia, Prática, Habilitações em Administração Escolar e Supervisão do Ensino; dos cursos de licenciatura: educação física, inglês, francês, língua portuguesa. Ciências sociais, história, geografia, ciências e matemática. Também foram atendidos alunos dos cursos de licenciatura: educação física, inglês, francês, língua portuguesa, ciências sociais, história, geografia, ciências e matemática, entre outras.

Como orientação para as práticas escolares e atividades extraclasse. Em 1977, Azanha escreveu a seguinte diretriz para a EA:

Desde alguns anos, o interesse e até mesmo a preocupação com a educação vem se acentuando extraordinariamente numa certa camada da população. Como consequência disso têm-se depositado esperanças crescentes e até certo ponto, infundadas na ação da escola. Espera-se dela talvez o milagre de produzir gerações futuras menos angustiadas e perplexas do que as atuais. Evidentemente, o próprio professor não poderia escapar a esse clima de entusiasmo. É nesse quadro, talvez, que se pode compreender a intensa procura de escolas que se anunciam como "escolas renovadas. Parece até que a renovação pedagógica fará de nossas escolas instituições capazes de realizar aquilo que as nossas ilusões nos fazem desejar da ação escolar. No entanto, na maior parte das vezes, os resultados práticos têm sido mais escassos do que as esperanças de pais e educadores. Talvez isso ocorra porque não haja concepções claras e inequívocas do que se chama de "renovação pedagógica". Muitas vezes, esses esforços de renovação são historicamente desenraizados, revelando um total desconhecimento dos clássicos do pensamento pedagógico, que desde há séculos vêm preconizando medidas, que, no entanto, esquecidas ou ignoradas, não são nem sequer discutidas e experimentadas. Teoricamente desinformado, o esforço de renovação pedagógica se esgota na adoção acrítica de novidades cujo valor educativo é sempre uma incógnita, mas que são alardeadas e difundidas como se delas dependesse todo êxito do ensino. Tudo se passa como se a simples substituição do antigo pela novidade fosse a garantia da excelência pedagógica. Não se trata aqui, evidentemente, de uma exaltação do antigo em detrimento do novo, mas a recusa de tomar a ordem temporal de aparecimento como o critério para apreciar os méritos de uma prática ou de uma concepção. Alguns aspectos desse estilo de renovação são facilmente assinaláveis. Por exemplo, tem-se dado uma exagerada ênfase à importância da criatividade, perdendo-se de vista, muitas vezes, o fato de que a simples originalidade não é algo que tenha um valor intrínseco. É claro que não se deve incutir um espírito de rebanho, mas é claro também que, muitas vezes, a singularidade de um comportamento pode nada ter de criativo ou original, mas deveria antes ser motivo de preocupação e de medidas preventivas. Do mesmo modo, é preciso que a liberdade do educando seja concebida, no plano individual, como uma complexa exigência interior que deve ser cultivada e estimulada, e não apenas confundida com a permissão de 
uma movimentação física inconsequente ou inoportuna em face da natureza das atividades. É preciso que professores e alunos compreendam que disciplina nem sempre pode ser entendida como uma restrição a qualquer liberdade, mas apenas como condição indispensável de trabalho individual ou coletivo (Plano Escolar Anual, 1977, p. 1-2).

Em seguida, Azanha define a finalidade da Escola de Aplicação e as condições para seu alcance:

Esta escola se propõe um trabalho diferente desse confuso estilo de renovação que de prático, se resume em permissões sucessivas e desavisadas, na complacência com os deveres não cumpridos e na tolerância sistemática com a indisciplina. O que visamos é o desenvolvimento dos indivíduos com capacidade de crítica. A capacidade de criticar a si próprio e a sociedade em que vive é o único ponto de apoio firme para desenvolvimento de homens criativos e livres. Contudo, não acreditamos que a capacidade de crítica possa ser diretamente ensinada. Mas acreditamos que ninguém a desenvolverá na ignorância ou no aprendizado insuficiente de um mínimo do acervo cultural da sociedade em que vive. Porque a capacidade de crítica depende para a sua expressão do domínio de um instrumental que não se obtém senão pelo estudo intensivo e sistemático. Por isso, o processo de estudo desta escola visará, sobretudo, não ao hipotético desenvolvimento de inefáveis hábitos e atitudes, mas à trivial e indispensável transmissão de conhecimentos. Os hábitos e as atitudes que compõem um espírito crítico não se desenvolvem formalmente, por isso a escola se propõe educar (no sentido de desenvolvimento de hábitos e atitudes) e não instruir (no sentido de aquisição de conhecimentos) persegue um fantasma. Ninguém se educa sem aprender algo, sem se instruir, como também ninguém se instrui sem que haja oportunidade de formar hábitos e desenvolver atitudes. Nessas condições, o empenho do professor em ensinar e o esforço do aluno em aprender são elementos indispensáveis num trabalho educativo sério. O que não é incompatível, evidentemente, com a amenidade dos métodos e a cordialidade do relacionamento. Nenhum método, técnica ou procedimento será imposto ao professor, mas nenhum deve ser permitido sem que ele seja capaz de justificá-lo em termos da sua importância para a formação do educando e não para simples distração do aluno. A escola é um lugar de trabalho- que pode e deve ser agradável- mas não de lazer. (AZANHA, 1987, p. 151,152).

Quanto ao ensino recreativo, Azanha apresenta o seguinte parecer:

Talvez o contraste mais nítido entre a escola de ensino tradicional e a de ensino renovado esteja no fato de que nesta diluiu-se completamente a distinção entre o brinquedo e o estudo. Até mesmo os livros didáticos perderam a antiga gravidade e procuram cada vez mais imitar as revistas de histórias em quadrinhos. Talvez se tente, com medidas desse tipo fazer crer que o estudo também é, ou pode, ou deve ser uma forma de recreação. O que é evidentemente falso, pois a recreação pode ser interrompida quando se quer (ou não se trata de recreação), enquanto que o estudo exige perseverança não obstante o tédio. (Azanha, 1978, p.19). 


\section{(cc) $\mathrm{BY}$}

Parece visível, portanto, o distanciamento das ideias de Azanha em relação aos teóricos da renovação pedagógica que, na época, eram amplamente estudados e debatidos entre os educadores, principalmente nos cursos superiores de formação de professores. Coube à coordenação técnica se reunir com os professores para a discussão da orientação de Azanha. Houve consenso por parte dos professores e dos responsáveis pela direção e coordenação da escola. Assim, a diretriz passou a nortear o Plano Escolar Anual e a orientação de todas as atividades docentes e técnico-administrativas da Escola de Aplicação. Neste sentido, após a identificação dos principais problemas e dificuldades da escola e as decisões para sua solução, era elaborada a proposta pedagógica do ano letivo de acordo com a seguinte orientação de Azanha:

O projeto pedagógico da escola é apenas uma oportunidade para que algumas coisas aconteçam e dentre elas o seguinte: tomada de consciência dos principais problemas da escola, das possibilidades de solução e definição das responsabilidades coletivas e pessoais para eliminar ou atenuar as falhas detectadas. Nada mais, porém isto é muito e muito difícil. A ideia de um projeto pedagógico, visando à melhoria da escola com relação às suas práticas específicas, será uma ficção burocrática se não for fruto da consciência e do esforço da coletividade escolar. Por isso, é ela, a escola, que precisa ser assistida e orientada sistematicamente, e seus membros temporários, os professores, não devem ser aperfeiçoados abstratamente para o ensino da sua disciplina, mas para a tarefa coletiva do projeto escolar. (Azanha, 2006, p. 96, 103).

Com base nesta orientação, o Projeto Pedagógico era alvo de constantes análises e revisões, tendo-se sempre em vista uma contínua melhoria da escola, especialmente nos aspectos pedagógicos. Para as atividades de planejamento, Azanha apresentou a seguinte orientação:

Num período de apenas uma semana não se pode pretender a elaboração de um planejamento global das atividades escolares para um ano. Mesmo deixando de lado a discutível ideia de que num período mais longo esse planejamento global era exequível, pode-se talvez afirmar que, de qualquer modo, ele não seria desejável. Porque um planejamento de tal forma abrangente obrigaria, no curso de sua execução, a tantas e tantas reformulações que haveria o risco de não se fazer outra coisa senão planejar e replanejar. A ideia de planejamento no início do ano escolar repousa na saudável preocupação em assegurar um mínimo de entendimento da conjugação de esforços entre pessoas que realizam fragmentos de uma tarefa comum e que por força da própria dinâmica do trabalho docente tendem a isolar-se. Embora esse eventual isolamento não seja necessariamente um mal, poderá, contudo, seja oportunidade de perda de vista dos objetivos comuns de todas as atividades escolares. Nessas condições, o fundamental na semana de planejamento será rediscutir os objetivos do processo educativo do ensino de $1^{\text {o }}$ grau, como ponto de partida para avaliação do papel de cada matéria nesse processo. E consequentemente, deverá se chegar à determinação dos conteúdos mínimos a serem alcançados no ensino de cada matéria, de modo a 
se assegurar sua efetiva contribuição à formação geral do aluno. Outros pontos a serem discutidos, como avaliação, recuperação, utilização de biblioteca etc., serão subordinados a esse ponto prioritário: o que é efetivamente indispensável ensinar em cada matéria e como fazê-lo. (AZANHA, p.137, p.23)

O planejamento constava de um trabalho conjunto - coordenação técnica e professores. Na década de 1970 predominavam várias teorias do ensino, principalmente as do então denominado progressismo. Azanha, refratário a outros movimentos de renovação pedagógica, afirma que há neste movimento um jogo verbal travestido de inovação pedagógica que poderia ser tolerado como inconsequente se não houvesse inconveniente da fraude intelectual, como, por exemplo, a de apresentar ideias alheias como próprias.

Outras inovações decorrentes do movimento de renovação pedagógica foram também alvo de críticas e de alerta ao professor. É o caso das atividades de pesquisa pelos alunos e da técnica de trabalho em grupo que podem implicar cópias sem indicação de fontes e mesmo “... a fraude de apresentar ideias alheias como próprias”. (AZANHA, p. 98, 105).

A propósito do conceito de didática, ou seja, de como ensinar, após uma explanação a respeito, Azanha conclui:

[...]. Embora tenhamos tratado o tema dos pressupostos da Didática numa perspectiva limitada da análise lógica, acreditamos ter fornecido nesta exposição, pelo menos, indicações de que o sonho de Comênio e também suas variantes históricas e atuais repousam numa ilusão. A de que a atividade de ensinar, no seu sentido amplo, possa ser exaustivamente regulada. $\mathrm{O}$ reconhecimento desse fato deve ter um efeito moderador no entusiasmo com que, às vezes, aderimos à esta ou àquela novidade no campo da Didática. Por outro lado, esta é uma conclusão muito positiva porque revela que o professor, na sua atividade criativa de ensinar, é um solitário, que por isso mesmo não deve esperar socorro definitivo de nenhum método ou modelo de ensino, por mais avançadas e sofisticadas que sejam as teorias que supostamente os fundamentam. (AZANHA, 1987, p.77).

\section{ATIVIDADES CULTURAIS E PROJETOS DE ESTUDO}

Os programas de ensino foram enriquecidos com várias atividades extraclasse incluídas no evento denominado "Semana cultural de outubro", a saber: campeonatos esportivos, peças teatrais e exposições artísticas, campeonatos esportivos, feiras de livros da literatura infantojuvenil. Também constava o coral da EA denominada "Os Pequenos Cantores da USP”. Outra atividade importante consistia em encontros dos alunos com repórteres, cronistas, publicitários, músicos, especialistas em assuntos científicos e autores da literatura infanto-juvenil. Quanto às disciplinas de francês e inglês foram organizadas duas salas para serem usadas como "clubinhos", em que eram desenvolvidas atividades com vistas ao enriquecimento da cultura 


\section{$(\mathrm{Cc}) \mathrm{EY}$}

dos alunos: conversação, canto, peças teatrais, filmes, sempre baseados na literatura francesa e inglesa.

O programa da área de Ciências Físicas e Biológicas incluiu atividades e programas extras relacionados com o estudo do meio ambiente e suas relações com a saúde, economia e cultura. Quanto à alfabetização, foram desenvolvidos programas tanto com base na linguística como na semiótica sendo que em ambos os casos, os resultados foram satisfatórios, uma vez que também foi dada ênfase na redação de textos diversos e na leitura intensiva e sistemática de livros da literatura infanto-juvenil de bons autores, selecionados com a orientação das bibliotecárias junto aos alunos de todas as séries. Nesse sentido. Também muito contribuíram para a aprendizagem e o aperfeiçoamento das habilidades da leitura e da escrita as atividades das áreas de artes plásticas e de ciências que incluíam redações de etiquetas de identificação, avisos, receitas, textos para peças teatrais, entre outras.

Diante dos bons resultados obtidos, a Escola de Aplicação, principalmente os pais, não mediram esforços para a implantação do ensino do então $2^{\circ}$ grau, atualmente Ensino Médio. Entretanto, em 1984, a escola foi alvo de uma crise que suscitou até a ideia de sua extinção, conforme manifestação do reitor da USP mediante ofício enviado ao diretor da FEUSP. Juntouse a este fato a crítica feita pelo professor Nélio Parra quanto ao relacionamento da EA com a FEUSP, principalmente no que se referia à pouca oferta de estágio aos alunos. Este fato constituiu o verdadeiro motivo do pedido de afastamento do Professor José Mário Pires Azanha da representação junto à EA e, mais ainda, da sugestão deste professor para pôr a EA em debate. O que só se concretizou em 1985.

No debate, Azanha expôs, com clareza, sua concepção e justificativa da Escola de Aplicação em termos de autonomia do professor para, num esforço coletivo, pôr em prática um projeto educativo escolar com vistas a um objetivo comum, semelhante, portanto, às escolas públicas, em todos os seus aspectos: administrativo, técnico, pedagógico. Naquele momento, Azanha argumentou em defesa do caráter propedêutico da formação escolar e do papel que a Escola de Aplicação desempenhava na formação de todos os seus alunos. Azanha insistia no fato de que o caráter democrático da instituição se situava exatamente na democratização do acesso. A escola era democrática por contar com um público variado e de todos os estratos sociais. Além disso, os inúmeros projetos que a instituição fomentava em termos pedagógicos favoreciam a dimensão crítica e criativa de uma forma de se lidar com o conhecimento que passava também pela democracia nas relações de ensino. Finalmente, a proposta pedagógica era feita pelo próprio pessoal responsável pela própria escola sendo que não se justificaria, portanto, o envio de pacotes preparados em instância superior porque é necessário respeitar a 


\section{$(\mathrm{Cc}) \mathrm{EY}$}

cultura própria de cada escola. No terceiro dia foram discutidos: o Regimento da Escola de Aplicação, Normas de estágio, além de outros documentos selecionados para análise e revisão. Também foram analisadas sugestões relativas à integração da EA com a Faculdade de Educação, principalmente no que se refere à articulação das duas instâncias especialmente quanto a projetos de pesquisa.

Também foram discutidas e aprovadas as providências necessárias para a implantação e funcionamento do curso de $2^{\circ}$ grau na Escola de Aplicação, considerando: objetivos, o caráter autotélico desse nível de ensino, o quadro curricular com vistas a uma formação geral, critérios para a seleção de professores com base no currículo e para matrícula de candidatos. Com a implantação do curso de $2^{\circ}$ grau, uma proposta nova foi lançada, dado que a ideia de uma formação geral, que contemplasse uma preparação propedêutica dos alunos, favorecia um projeto escolar voltado para uma dimensão humanista, a qual balizou a própria formulação da mesma proposta de que viesse a ser criado esse que se tornaria depois o Ensino Médio. Podese mesmo dizer que a Escola de Aplicação antecipou em sua prática aquilo que viria a ser consubstanciado na LDB de 1996. Tratava-se de um ensino que estivesse para além das habilitações ainda existentes no segundo grau. Um ensino que passava por uma formação humanista e que teve como consequência o fato de os alunos egressos do curso de $2^{\circ}$ grau serem aprovados com facilidade nos cursos de nível superior. Hoje são médicos, advogados, publicitários, atores de teatro, dentistas, músicos (inclusive um faz parte da Orquestra Sinfônica de Moscou); nutricionistas, antropólogos, engenheiros e assim por diante.

Assim, podemos afirmar que o principal requisito para a formação de alunos com capacidade de crítica consiste na aquisição de uma cultura geral mediante muito estudo e diálogo, conforme sempre foi objeto do ensino na Escola de Aplicação. Salienta-se, assim, a importância da orientação de Azanha para a organização e funcionamento desta escola.

\section{REFERÊNCIAS}

AZANHA, J. M. P. Experimentação educacional: uma contribuição para sua análise. São Paulo: Edart, 1974.

AZANHA, J. M. P. Alain ou a pedagogia da dificuldade. Revista da Faculdade de Educação. São Paulo, v. 4, n. 1, 1-145, jun. 1978.

AZANHA, J. M. P Educação, alguns escritos. São Paulo: Ed. Nacional, 1986

AZANHA, J. M. P. Cultura escolar brasileira. Revista USP, São Paulo, n. 8, p. 65-69, fev. 1991. 
AZANHA, J. M. P. Uma ideia em pesquisa educacional. São Paulo: Edusp, 1992.

AZANHA, J. M. P. Educação: temas polêmicos. São Paulo: Martins Fontes, 1995.

AZANHA, J. M. P. A formação do professor e outros escritos. São Paulo: Senac, 2006.

BEISIEGEL, C. R. Origens das orientações da pesquisa educacional na Faculdade de Educação. Educação e Pesquisa, São Paulo, v. 29, p. 357-364, jul./dez. 2003.

CARVALHO, J. S. P. Educação, cidadania e direitos humanos. Petrópolis, RJ: Vozes, 2004.

CUNHA, L. A. A educação e o desenvolvimento social no Brasil. Rio de Janeiro: Ed. Francisco Alves, 2009.

CONGREGAÇÃO/FEUSP. Atas - 1984 a 1985. São Paulo, Faculdade de Educação da USP.

GORDO, N. Escola de Aplicação da FEUSP: relatório de atividades entre 1976-

1989. Estudos e Documentos, Feusp, São Paulo, v. 18, 1990.

GUSDORF, G. Professores para quê? Lisboa: Livraria Morais Editora, 1967.

LIMA, R. A educação no Brasil: o pensamento e atuação de José Mário Pires Azanha. 2005. Tese (Doutorado em Educação) - Faculdade de Educação da Universidade de São Paulo, 2005

NÓVOA, A. A relação escola-sociedade: novas respostas para um velho problema para a formação de professores. 4. ed. São Paulo: Editora Unesp, 1998.

ORTEGA Y GASSET, J. El quijote en la escuela. Obras completas. Madrid: Aliança, 1987. PEIRCE, C. S. Semiótica. São Paulo: Perspectiva, 1977.

SANTAELLA, M. L. O que é semiótica? São Paulo: Brasiliense, 1983 (Coleção Primeiros Passos).

SEVERINO, Antônio J. A diversidade e o cotidiano escolar. Idéias. FSE, São Paulo: SMEP/SP, 2000.

SOUZA, C. P. A diversidade e o trabalho escolar. São Paulo: SMEP/SP/Fafe-Feusp, 2005.

UNIVERSIDADE DE SÃO PAULO. Debate: Escola de Aplicação: São Paulo, Faculdade de Educação, 1985.

VASCONCELOS, C. dos S. Coordenação do trabalho pedagógico numa perspectiva libertadora. São Paulo, USP/SMEP; mimeo., 1995. Projeto Capacitação de Coordenadores Pedagógicos da Rede Municipal de Ensino de São Paulo.

VEYNE. P. Como se escreve a história. Tradução de António José da Silva Moreira. Lisboa: Edições 70, 1971. 


\section{(cc) $\mathrm{Br}$}

ZAIA, I. B. A história da educação em risco: avaliação e descarte dos documentos do arquivo da Escola de Aplicação (1958-1985). 2003. Dissertação (Mestrado em Educação). Faculdade de Educação da Universidade de São Paulo.

Recebido em: 26 de outubro de 2021

Aceito em: 20 de dezembro de 2021 